\title{
3D Printing in Biomedical Applications
}

\author{
Venkatraman Balasubramaniam*, Senthil Murugan Subramanian, Venkatesh P. Kannan, Steve M.R. Joseph
}

Mepco Schlenk Engineering College (Autonomous), Sivakasi 626005, India

Corresponding Author Email: venkatramanb@mepcoeng.ac.in

https://doi.org/10.18280/ti-ijes.630104

Received: 28 January 2019

Accepted: 15 March 2019

\section{Keywords:}

enzymatic incubation medium, birth similar organs, $3 D$ bio-printing, additive manufacturing, embryonic stem cell, placental fluid

\begin{abstract}
This study deals with the 3D Bio-Printing technology, a type of additive manufacturing in which the 3D object is imitated to be visual within the allocated period of time interval that resembles similar in considered aspects of real world objects like kidney, bones and many other body parts. The material used includes the powders of polymer mass that are solidified by directional laser heating. While talking about Bio-Printing, the material used are living tissues, calcium source, vascular tissue, placental fluid, embryonic stem cell etc., and the entire organ is regenerated from the tissue, which is being printed in the enzymatic incubation medium. The regenerated organ is similar to the patient's organ. The information of the patient's organ get read from many scanning devices. The making of organ is controlled by the speed of filling tissue, temperature at which the process is carried out, bonding agent to bond the tissues together, incubation medium, type of tissue, body immunity, stem cell growing phenomenon, filler head movement respective to all the axes, slicing path, etc., The produced artificial organ (human bone, human kidneys, bladder, etc.,) can be replaced with the defected organ. Thus, the controlled action of all the parameters can lead to the organic replacement of the birth similar organs.
\end{abstract}

\section{INTRODUCTION}

3D printing is the process by which, the prototype model of the real world object is produced, that aids in analysis of various aspects. 3D printing concept arises from the RP Method, in which the fluid fill is replaced by the layer of additive powder fill, which gets solidified due to the intensive laser head [1]. Laser solidifies the powder of thermosetting plastic, and then the new layer of powder is filled by special arrangement, here the depth of each fill depends on the depth of the additive layer. The operation is repeated up to the attainment of required shape and size of the component is achieved. The operation depends on the parameters such as type of laser and the pointed laser radius which controls the thickness of additive single layer (i.e. the radius of laser spot is the single fill thickness, if we want two time thickness, we have to led the laser to move two times), material of the powder, depth of layer fill, speed of laser head movement, distance between the point the laser tip and the solidifying powder layer. The $3 \mathrm{D}$ printing is adopted to print the complex and intricate components. It is adopted at the place where the subtractive machining is not possible.

\section{PRINCIPLE AND FACTORS TO BE CONSIDERED IN 3D BIO-PRINTING PROCESS}

The 3D Bio-Printer works on the principle of RAPID PROTOTYPING. It is one of the additive manufacturing processes, where layer by layer addition of material based on the sliced CAD Model. The CAD model defines the shape and size of final required object.

\subsection{Mechanism of printing artificial human kidney}

$3 \mathrm{D}$ biological printer is the device that makes use of living tissues, calcium material, connecting tissue, protein (keratin substance), etc. and it is built in the sequence of sliced patterns. The patterns are then made to form the real object. It absolutely does the function of the organ. (Kidneys, bones, skull, heart valve, etc.,). Scanning electron microscope image of RED BLOOD CELL shows the diameter of RBC as 6-8 micrometers in diameter, while urea and other components present in the human urination is of diameter 9 to 12 Armstrong. Thus, the filtering of blood along with impurities is simple with the use of set of Nanotubes. This nanotubes allow the impurities to pass through, but it doesn't allow the blood cells to pass through it. Thus, the impurities are getting collected from the one end and allowed it to flow through the collecting tube followed by storing in the bladder. Scaffolding is a temporary structure used to support people and material in the construction or repair of buildings and other large structures [2]. It is usually a modular system of metal pipes or tubes, although it can be from other materials. Scaffold structure is the base for making kidney in this process. The various contents present in the urine are salts (Na, K, P etc.,), vitamin, water, urea, creatinine, etc., The atomic radius of urea is comparatively smaller than the other components present in the urine. Thus removal of the urea is made easy and the collection of urine in the bladder can also be made.

\subsection{Major factors affecting the 3D-printed kidney in body}

The kidney should purify the blood for that the nanotubes 
arrangement is provided in the tubular-spiral-bundle, blood enters at one side of the tube during purification and leaves at the other side of the tube after purification. The two major factors that affects filtering is,

\section{(i) Blood Pressure}

Fluid in the tube exerts circumferential pressure to the walls of the tube, the filtering is made easier. A person's normal blood pressure is the dialyzing source. It works faster for the persons having higher blood pressure and slower for the person having the low blood pressure.

\section{(ii) Body temperature}

The presence of foreign particles in the body and the food digestion in the alimentary canal makes the temperature of the body to increase. The killing of foreign body (virus, bacteria, etc.,) by White Blood Cell makes the body temperature to increase and speeds up the action of filtering.

\subsection{Connection with body tissue}

The implanted kidney should compatible with the body tissues and blood vessels, and then only the implantation is stable [3]. For that purpose the outermost layer is made to adhere with the body cells.

The outer most layer of printed kidney is coated with pyrolytic carbon, and secured to the surrounding tissue with a mesh of woven fabric called Dacron ${ }^{\mathrm{TM}}$ (du Pont's trade name for polyethylene terephthalate). The mesh allows for the body's tissue to grow while incorporating the kidney. Figure 1 shows the Micrograph of soft tissue.

\subsubsection{Materials}

The material used to build the layer of kidney is biopolymers, which are compatible to the body tissues, blood cells and immune system. Biopolymers are polymers produced by living organisms.

\subsubsection{Polymer}

Cellulose, starch, proteins, peptides, DNA and RNA are the examples of biopolymers.

\subsubsection{Monomer}

The monomeric units, respectively, are sugars, amino acids, and nucleotides. Cellulose is both the most common biopolymer and the most common organic compound on Earth. About $33 \%$ of all plant matter is cellulose.

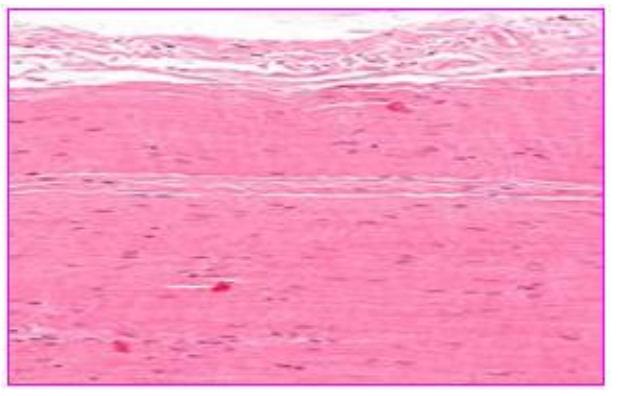

Figure 1. Micrograph of a piece of soft tissue (tendon)

Some biopolymers are biodegradable (i.e. they are broken down into $\mathrm{CO}_{2}$ and water by some biological reagents). In addition, some of these biodegradable biopolymers are compostable [4]. That is, they can be put into an industrial composting process and will break down by $90 \%$ within 6 months. Biopolymers that do this can be marked with a 'compostable' symbol, under European Standard EN 13432 (2000). Packaging marked with this symbol can be put into industrial composting processes and will break down within 6 months (or less). An example of a compostable polymer is PLA film under 20 micrometer thickness. Films which are thicker than that do not qualify as compostable.

\subsubsection{Soft tissue material}

In anatomy, soft tissues are the tissues that connect, support, or surround other structures and organs of the body, not being bone [5]. Soft tissue includes tendons, ligaments, fascia, skin, fibrous tissues, fat, and synovial membranes (which are connective tissue), and muscles, nerves and blood vessels (which are not connective tissue). Soft tissues have the potential to grow and remodel reacting to chemical and mechanical long term changes. The rate the fibroblasts produce tropocollagen is proportional to these stimuli (tablets, syrup, can be feed orally). So, soft tissues like tendons, ligaments, fascia, fibrous tissues, fat and synovial membrane can be used in 3D printing of birth similar organs. Various factors of 3D Printed Kidney is shown in Figure 2.

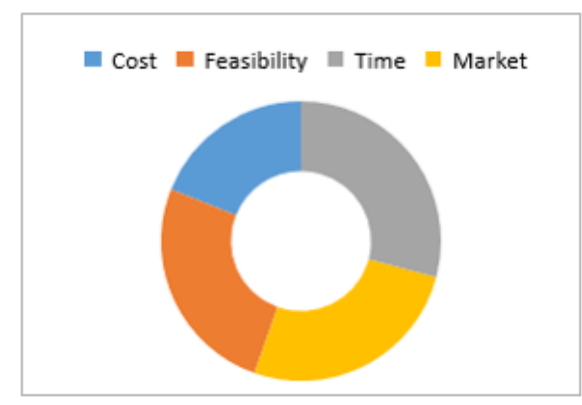

Figure 2. Various factors of 3D Printed Kidney

\section{3D SKIN PRINTING}

The skin of kidney should compatible to the body tissues and immune system. The kidney should combine with the body cells at the outermost surface. Bio-compatible materials, say, Poly- Jet photopolymer (MED610) is a rigid medical rapid prototyping material. It features high dimensional stability and colorless transparency [6]. The material is ideal for applications requiring prolonged skin contact of more than 30 days and short-term mucosal-membrane contact of up to 24 hours. Poly-Jet photopolymers combine a wide variety of material properties with thin layers, so we can create true product realism in our prototypes.

Object 3D Printers are the only additive manufacturing systems in the world than give we multi-material flexibility. We can combine materials within the same $3 \mathrm{D}$ printed model or in the same print job, enabling a wealth of applications such as over-molding, grayscale coloring, simultaneous prints in different materials and more [7]. We can also combine two materials during printing to create composite Digital Materials with very specific properties. The skin material slowly disintegrates with the body tissues and allows the body tissue to combine with the pyloric carbon at the area where there is the space for combination is being achieves [8]. The skin material disintegrates as patches, thus the area of patches is combined first. The artificial printed skin used here can be used heal the wounds, sores, burns, and the application where temporary skin is needed. A typical 3D $\mathrm{CAD}$ model of natural human kidney is given in Figure 3 


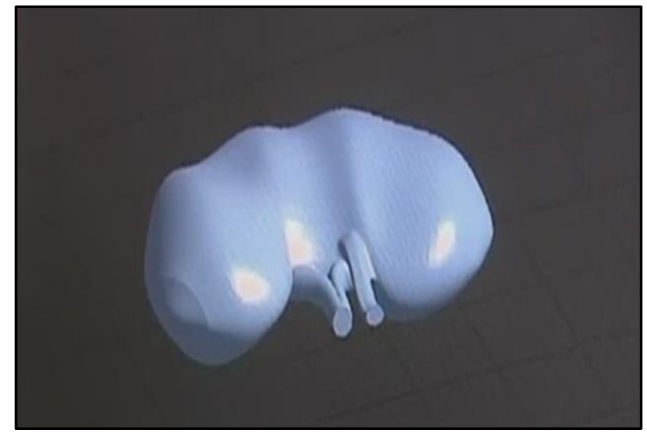

Figure 3. A typical 3D CAD model of natural human kidney

\subsection{Process parameters involved in 3D Bio-Printing}

The making of organ is controlled by,

- $\quad$ Speed of filling Biopolymers.

- Temperature at which the process is carried out

- Bonding agent to bond the tissues together

- Incubation medium

- Type of tissue

- Stem cell growing phenomenon

- Filler head movement respective to all the axes

- $\quad$ Slicing path, etc.,

\section{VARIOUS SECTIONS OF 3D PRINTED KIDNEY}

The various sections of the kidney that are to be made with the use of this technology are as follows,

(i) Bio-Vessels

(ii) Bio-tubules

(iii) Micro-tubes (spiral) to filter blood and filter active elements

(iv) Chamber to collect urine

(v) Chamber to initial storage of blood

(vi) Minute chambers at the surface.

\subsection{Bio-vessels and Bio-tubules}

Vessels for blood flow in and out having connecting tissue at the end to bond with body blood vessels while the BioTubules connect with the urinary bladder. Tubular-spiralmicro tubes of 500 micrometer in diameter and coils up to the size of the kidney and to lengthen of the filtering path [9]. Carbon micro-tubes (Figure 4) are among the numerous candidates for tissue engineering scaffolds since they are biocompatible, resistant to biodegradation and can be functionalized with biomolecules.

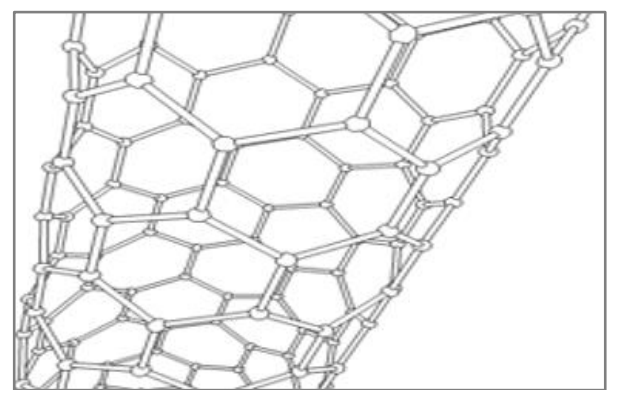

Figure 4. A typical carbon microtube of 500 micrometer diameter
Tubular-spiral-micro tubes of 500 micrometer in diameter and coils up to the size of the kidney and to lengthen of the filtering path.

Carbon micro-tubes are among the numerous candidates for tissue engineering scaffolds since they are biocompatible, resistant to biodegradation and can be functionalized with biomolecules.

\subsection{Minute chamber at the surface}

Minute chambers present at the surface to grow connective tissues. Tissue engineering utilize living cells as engineering materials [10]. Examples include using living fibroblasts in skin replacement or repair (similar to soft tissue), cartilage repaired with living chondrocytes, or other types of cells used in other ways. These fibroblast materials occupy the outermost surface of the printed kidney, and it starts growing after the skin of kidney disintegrates as patches. The two chambers available are

(i) Chamber to pressurize blood initially,

(ii) Chamber to collect the filtered urine.

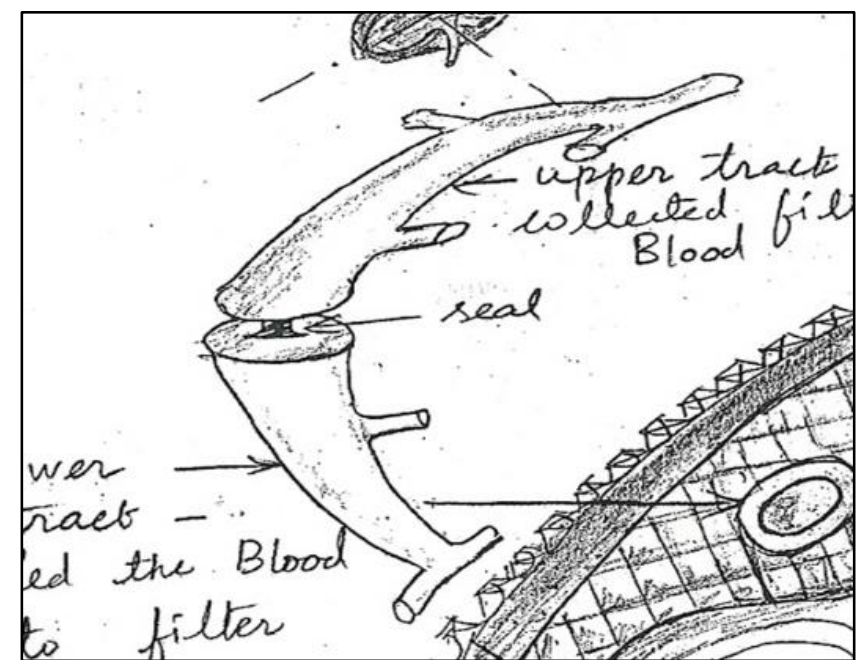

Figure 5. Proposed model of blood supply chamber that is being pressurized by pressurizing chamber

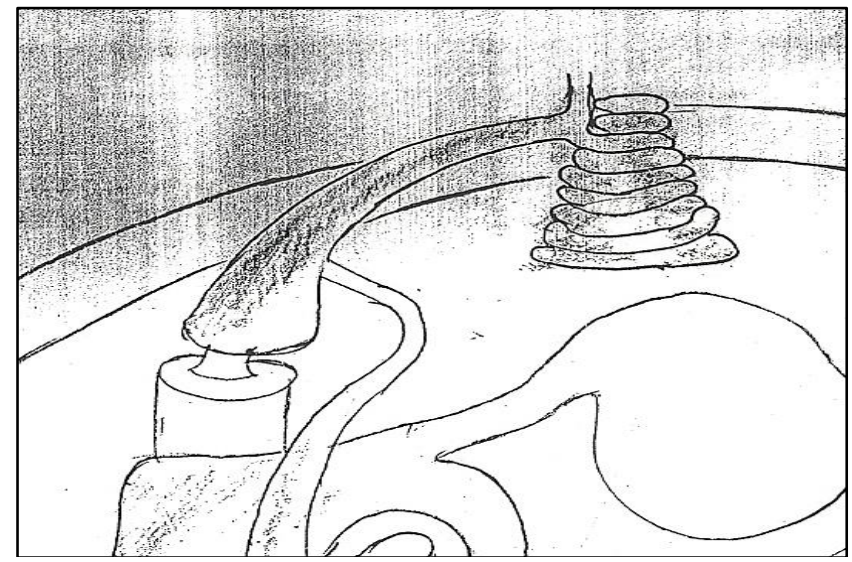

Figure 6. Proposed model of upper chamber that receives the filtered blood and active elements

Proposed model of blood supply chamber is shown in Figure 5 and Figure 6 shows the upper chamber for filtered blood. 


\section{KIDNEY MODEL}

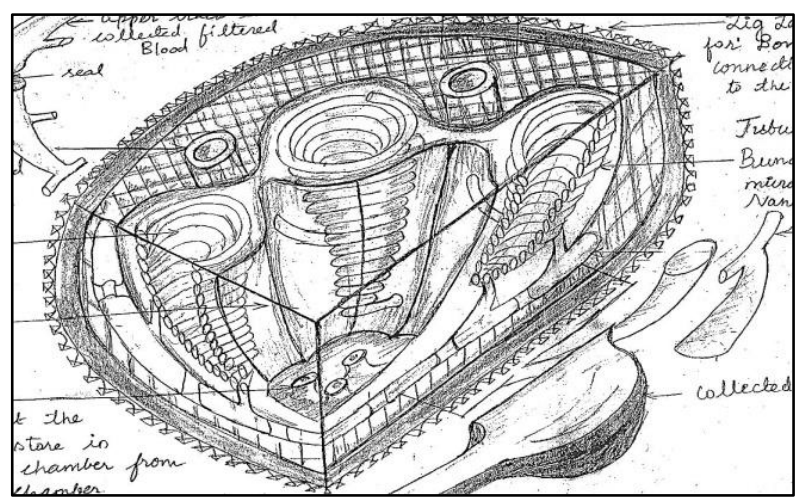

Figure 7. Cross-section of the proposed kidney model 7.

Cross section of proposed kidney model is given in Figure

\subsection{Slicing}

Slicing is (in Figure 8) done by SLIC3R Software and it determines the path of filler head.

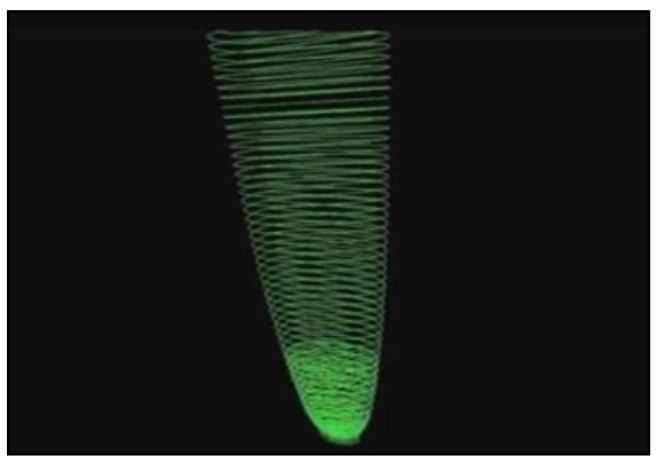

Figure 8. A model of slicing done using the software

\subsection{Kidney printing}

The printing process is similar to the process of rapid prototyping. The process of printing the kidney is by using a highly advanced 3D Bio-Printer that consists of an enzymatic incubation medium.

\subsection{Proposed design of artificial human kidney}

The kidney is the filtering device, filters blood to get away from impurities present in the blood. The filtering action of kidney is done in glomerulus tubule. In artificial kidney, it was done in micro tubule consists of nano-pores. Since, the blood flow is due to pressure of blood [11]. This pressure is enough for the filtering circumferential action to takes place.

\subsection{Active element recapture}

The various elements present in the urine (Say, $\mathrm{Na}, \mathrm{K}$, $\mathrm{H}_{2} \mathrm{O}$, etc.,) are necessary for the effective functioning of body. This can be captured with the help of capillary tube contains pores of diameter 10-12 meters [12]. The wastes such as uric salts, creatinine, etc., are not able to enter the pica porous tube. Thus, the second phase filtering filters the active elements form the urination and the elements are mixed up with the filtered blood. The excretion also consists of some reusable materials that aid in the proper functioning of the human muscular system for a healthy well being.

The atomic radius of the various components present in our blood are as follows.

\section{For $R B C, W B C: 6$ Micrometer (avg)}

For Urea, Creatinine: 9 Nanometer to 1 Armstrong

For Active Salts: 1 Pico meter to 12 Pico meter

\section{THE PROCESS OF FILTERING THE BLOOD}

The process flow of the filtration of the human blood by the proposed model of the 3D Bio-Printed kidney is depicted in the Figure 9. The blood is to be pressurized before it even enters the 3D Printed kidney. So, the pressurization is done $b$ using the temperature that prevails in the human body. This is then followed by the flow through the micro tubules comprising the holes in the nano-size. Hence they are called nano-pores. Here, the filtering action takes place at its core. Then the storage of impurities in collection chamber takes place. The next main process is the active element recapturisation. The process of capturing (Figure 10) is done mainly because of the presence of some or many of the vital elements in the excreted blood that aids in the absorption of minerals. The might not be sent out of the body along with the waste [13]. This is the reason for not limiting the process only with the nano-pore filtration process through the nano tubes present.

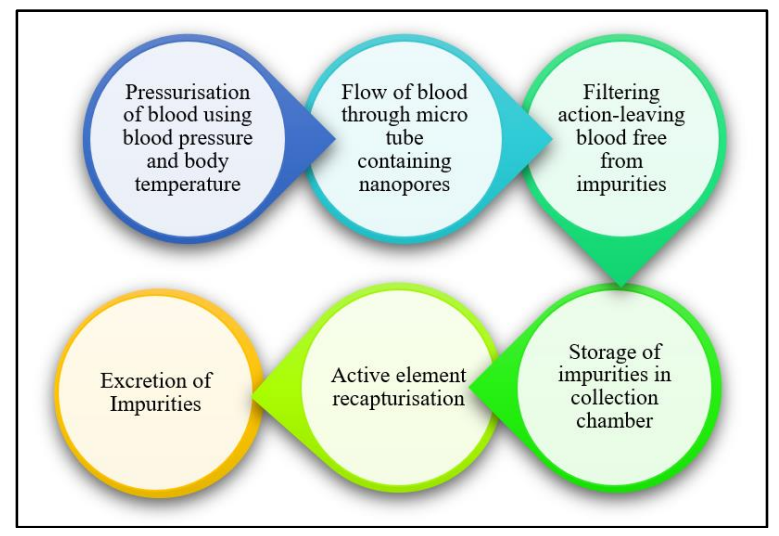

Figure 9. Process flow chart

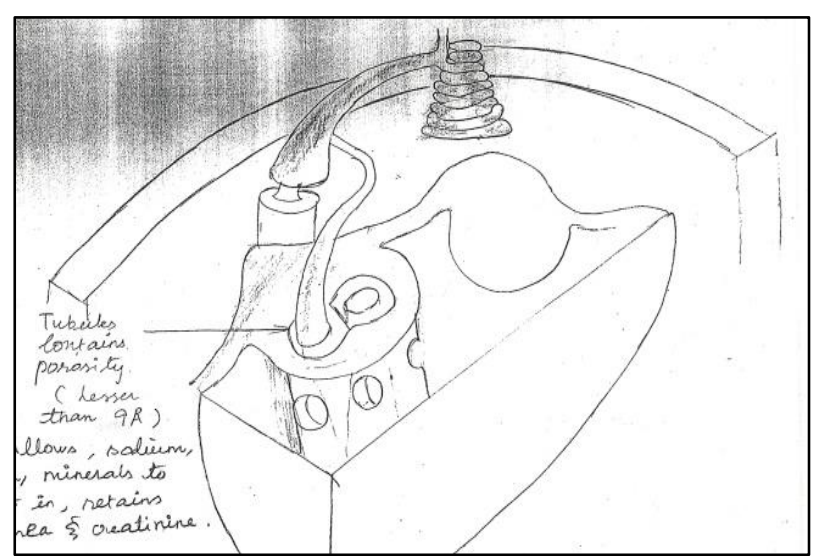

Figure 10. Part in the proposed model where Active element recapture is done 


\section{PARAMETERS FOR SIMULATION USING MATLAB PROGRAMMING}

There are some of the parameters (Figure 11) to be considered for simulating the proposed kidney model using Matlab Programming. The parameters to be taken into account are being discussed as follows.

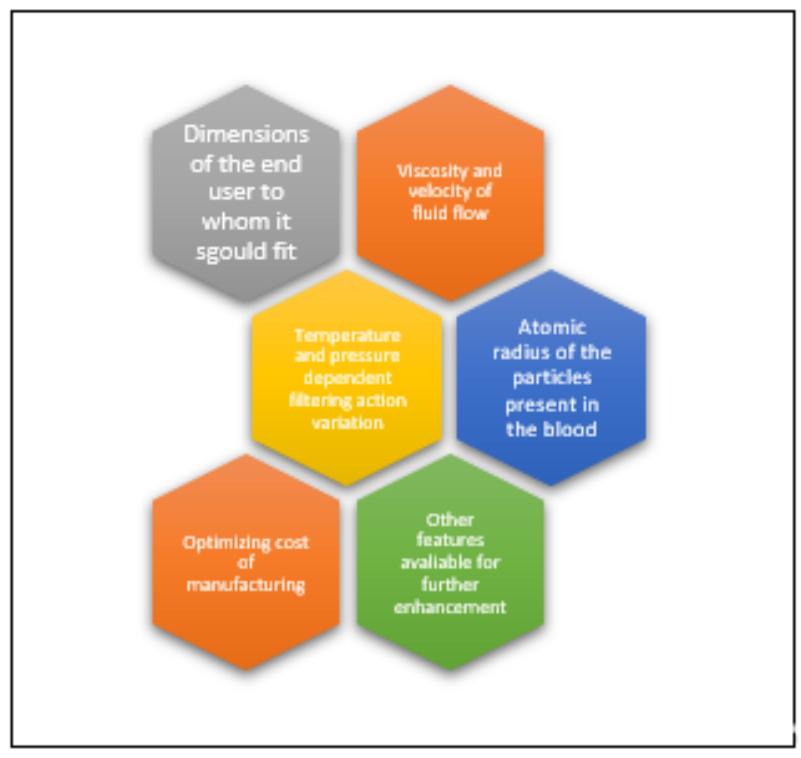

Figure 11. Process parameters in Matlab Programming

\section{COMPARISON OF PARAMETERS}

A comparison is being shown in Table 1 between human kidney and 3D bio-printed artificial kidney proposed in this study.

Table 1. Comparison of natural and proposed kidney model

\begin{tabular}{|c|c|c|}
\hline S. No. & $\begin{array}{l}\text { NATURAL HUMAN } \\
\text { KIDNEY }\end{array}$ & $\begin{array}{l}\text { PROPOSED 3D BIO- } \\
\text { PRINTED KIDNEY }\end{array}$ \\
\hline 1 & $\begin{array}{c}\text { Made of natural blood } \\
\text { vessels, cortex, crown } \\
\text { etc., }\end{array}$ & $\begin{array}{l}\text { Made of biopolymer } \\
\text { blood vessels, connective } \\
\text { tissues, soft tissues, } \\
\text { fibroblasts etc., }\end{array}$ \\
\hline 2 & $\begin{array}{l}\text { Nephron's glomerulus } \\
\text { tubule is the filtering } \\
\text { agent. }\end{array}$ & $\begin{array}{l}\text { Micro-tube contains } \\
\text { nanopores is the filtering } \\
\text { agent. }\end{array}$ \\
\hline 3 & $\begin{array}{l}\text { Active element } \\
\text { recapture by distal } \\
\text { convolute tubule, } \\
\text { ascending and } \\
\text { descending limp of } \\
\text { 5enley, proximal } \\
\text { convolute tubule. }\end{array}$ & $\begin{array}{c}\text { Active element recapture } \\
\text { by separate nanotube of } \\
\text { diameter less than a } \\
\text { nanometer. }\end{array}$ \\
\hline 4 & $\begin{array}{l}\text { Skin of kidney is } \\
\text { bonded to body tissues } \\
\text { and blood vessels by } \\
\text { birth. }\end{array}$ & $\begin{array}{l}\text { Skin of kidney is made of } \\
\text { temporary membrane, } \\
\text { which disintegrates as } \\
\text { patches and led the } \\
\text { formation of connectivity } \\
\text { between outer skin with } \\
\text { body tissue by fibroblast } \\
\text { growth. }\end{array}$ \\
\hline
\end{tabular}

\section{APPLICATIONS}

The 3D BIO-PRINTER paves its main application in manufacturing and medicinal field (Dual collaboration). In manufacturing field, prototype of the component can easily be made as the same principle of 3D Printer. The bones of human body are made based on the above explained process and are succeeded. The various organs like lungs, heart, liver, ear, bones, etc., can be made with the help of this $3 \mathrm{D}-\mathrm{BIO}$ PRINTER.

\section{CONCLUSION}

There is a fact that the 3D Bio-Printer can print the object as it is being manufactured by a conventional 3D Printer. But, the conventional 3D Printer cannot manufacture the object as manufactured by that of the 3D Bio-Printer. 3D Bio-Printing aids in person's organ failure treatment by replacement of birth similar organ in place of defective one. Thus it can save the human's life. The artificial kidney can be coupled with the dialyzer machine and used for treatment. The various 3DPrinted organs can be produced by the technique similar to the one mentioned above.

\section{ACKNOWLEDGEMENT}

Sincere thanks to the Department of Mechanical Engineering and Department of Bio-Technology, Mepco Schlenk Engineering College for the constant support rendered.

\section{REFERENCES}

[1] Hasenbank MS, Edwards T, Fu E, Garzon R, Kosar TF, Look M, Mashadi-Hossein A, Yager P. (2008). Demonstration of multi-analyte patterning using piezoelectric inkjet printing of multiple layers. Analytica Chimica Acta 611(1): 80-88. https://doi.org/10.1016/j.aca.2008.01.048

[2] Allain LR, Stratis-Cullum DN, Vo-Dinh T. (2004). Investigation of microfabrication of biological sample arrays using piezoelectric and bubble-jet printing technologies. Analytica Chimica Acta 518(1-2): 77-85. https://doi.org/10.1016/j.aca.2004.04.065

[3] Whitesides. (1991). Molecular self-assembly and nano chemistry: A chemical strategy for the synthesis of nanostructures. Science 254(5036): 1312-1319. https://doi.org/10.1126/science.1962191

[4] Loninia L, Accoto D, Petroni S, Guglielmelli E. (2008). Dispensing an enzyme-conjugated solution into an ELISA plate by adapting ink-jet printers. Journal of Biochemical and Biophysical Methods 70(6): 11801184. https://doi.org/10.1016/j.jbbm.2007.05.003

[5] Schubert C, Van Langeveld MC, Donoso LA. (2014). Innovations in 3D printing: a $3 \mathrm{D}$ overview from optics to organs. Br J Ophthalmol 98(2): 159-161.

[6] Ursan I, Chiu L, Pierce A. (2013). Three-dimensional drug printing: A structured review. Journal of the American Pharmacists Association 53(2): 136-144. https://doi.org/10.1331/JAPhA.2013.12217

[7] Mertz L. (2013). Dream it, design it, print it in 3-D: 
what can 3-D printing do for you. IEEE Pulse 4(6): $15-$ 21. https://doi.org/10.1109/MPUL.2013.2279616

[8] Gross BC, Erkal JL, Lockwood SY. (2014). Evaluation of $3 \mathrm{D}$ printing and its potential impact on biotechnology and the chemical sciences. Analytical Chemistry 86(7): 3240-3253. https://doi.org/10.1021/ac403397r

[9] Ozbolat IT, Yu Y. (2013). Bioprinting toward organ fabrication: Challenges and future trends. IEEE Transactions on Biomedical Engineering 60(3): 691699. https://doi.org/10.1109/TBME.2013.2243912

[10] Bertassoni LE, Cecconi M, Manoharan V, Nikkhah M, Hjortnaes J, Cristino AL, Barabaschi G, Demarchi D, Dokmeci MR, Yang Y, Khademhosseini A. (2014). Hydrogel bioprinted microchannel networks for vascularization of tissue engineering constructs. Lab on a Chip. 14(13): 2202-11. https://doi.org/10.1039/c4lc00030g
[11] Lipson H. (2013). New world of 3-D printing offers completely new ways of thinking. IEEE Pulse 4(6): 1214. https://doi.org/10.1109/MPUL.2013.2279615

[12] Khaled SA, Burley JC, Alexander MR, Roberts CJ. (2014). Desktop 3D printing of controlled release pharmaceutical bilayer tablets. International Journal of Pharmaceutics 461(1-2): https://doi.org/10.1016/j.ijpharm.2013.11.021

\section{NOMENCLATURE}

$3 \mathrm{D}$

Three Dimensional

\section{Greek symbols}

$\mu \mathrm{m} \quad$ Micrometer $\left(10^{-6}\right.$ meter $)$ 